\title{
Risk factors for hearing loss in infants under universal hearing screening program in Northern Thailand
}

This article was published in the following Dove Press journal:

Journal of Multidisciplinary Healthcare

24 December 2015

Number of times this article has been viewed

\author{
Watcharapol Poonual' \\ Niramon Navacharoen ${ }^{2}$ \\ Jaran Kangsanarak ${ }^{2}$ \\ Sirianong Namwongprom ${ }^{3}$ \\ 'Clinical Epidemiology Program, \\ ${ }^{2}$ Department of Otolaryngology, \\ ${ }^{3}$ Department of Radiology, Faculty \\ of Medicine, Chiang Mai University, \\ Chiang Mai, Thailand
}

Objective: To define the risk factors for hearing loss in infants (aged 3 months) under universal hearing screening program.

Materials and methods: A total of 3,120 infants (aged 3 months) who underwent hearing screening using a universal hearing screening program using automated otoacoustic emission test between November 1, 2010 and May 31, 2012 in Uttaradit Hospital, Buddhachinaraj Hospital, and Sawanpracharuk Hospital (tertiary hospitals) located in Northern Thailand were included in this prospective cohort study.

Results: Of the 3,120 infants, 135 (4.3\%) were confirmed to have hearing loss with the conventional otoacoustic emission test. Five of these 135 infants (3.7\%) with hearing loss showed test results consistent with auditory brainstem responses. From the univariable analysis, there were eleven potential risk factors associated with hearing deterioration. On multivariable analysis, the risk factors independently associated with hearing loss at 3 months were birth weight 1,500-2,500 g (risk ratio [RR] 1.6, 95\% confidence interval [CI] 1.1-2.6), APGAR score $<6$ at 5 minutes (RR 2.2, 95\% CI 1.1-4.4), craniofacial anomalies (RR 2.5, 95\% CI 1.6-4.2), sepsis (RR 1.8, 95\% CI 1.0-3.2), and ototoxic exposure (RR 4.1, 95\% CI 1.9-8.6).

Conclusion: This study concluded that low birth weight, APGAR score $<6$ at 5 minutes, craniofacial anomalies, sepsis, and ototoxic exposure are the risk factors for bilateral hearing loss in infants (aged 3 months) and proper tests should be performed to identify these risk factors. As an outcome, under the present circumstances, it is suggested that infirmary/physicians/general practitioners/health action centers/polyclinics should carry out universal hearing screening in all infants before 36 weeks. The public health policy of Thailand regarding a universal hearing screening program is important for the prevention of disability and to enhance people's quality of life.

Keywords: infant, universal hearing screening, risk factors, bilateral ears, cohort study

\section{Introduction}

Identification of all the infants (aged 3 months) with hearing loss should be done as early as possible to enable early treatment. Initial hearing screening has been perceived as the forecaster of hearing loss in infants. ${ }^{1}$ The aim of universal hearing screening was to recognize hearing loss at an early age and provide suitable amplification and treatment at 3 months of age. Early hearing problem detection is supported in infants to reduce the effect of hearing loss on learning, social and emotional progression as it is considered the greatest tool for conversation acquirement ${ }^{2,3}$ by a multidisciplinary team (otolaryngologists, pediatricians, audiologist, audiology technicians, and nurses). ${ }^{4,5}$ This research acts as a primary article for identifying risk factors in infants (aged 3 months) under the universal hearing screening program from three
Correspondence: Sirianong Namwongprom Department of Radiology, Faculty of Medicine, Chiang Mai University, Chiang Mai, Thailand 50200

Email sirianong.n@cmu.ac.th (c) (1) (-) $\odot 2016$ Poonual et al. This work is published by Dove Medical Press Limited, and licensed under Creative Commons Attribution - Non Commercial (unported, 33.0) License. The full terms of the License are available at http://creativecommons.org/licenses/by-nc/3.0/. Non-commercial uses of the work are permitted without any further permisso how to request permission may be found at: http://www.dovepress.com/permissions.php 
hospitals, of a tertiary care center located in Northern Thailand (including Uttaradit Hospital, Buddhachinaraj Hospital, and Sawanpracharuk Hospital). The infants were selected, as suggested by the Joint Committee of Infant Hearing. ${ }^{6}$ The screening test was the otoacoustic emission (OAE) test. It is accomplished in a few minutes and can be performed without an audiologist. The outcomes are a "pass" or a "refer", where those who obtained a "pass" are considered to have a hearing loss no more than $35 \mathrm{~dB}$ and those who obtained a "refer" are referred for more testing. Hearing loss is verified in three out of 1,000 infants, ${ }^{1-3,6-8}$ but the frequency extent to influence is $2 \%-5 \%{ }^{1,2}$ in the high-risk group that comprises infants with low birth weight, craniofacial anomaly, sepsis, and in consequences of ototoxic medication. Among low-risk cases, the frequency of hearing loss was extremely low. This research was aimed at identifying the risk factors for hearing loss in infants (aged 3 months) under the universal hearing screening program.

\section{Materials and methods Study design}

This was a prospective cohort study aimed at identifying the risk factors associated with hearing loss of all infants (aged 3 months) in Uttaradit Hospital, Buddhachinaraj Hospital, and Sawanpracharuk Hospital, the tertiary hospitals located in Northern Thailand between November 1, 2010 and May $31,2012$.

\section{Study population}

All infants were entered in the study, both the "normal" group and the high-risk group based on the "high-risk" criteria of the Joint Committee on Infant Hearing $1994{ }^{6}$

\section{Inclusion criteria}

All infants in the three hospitals who passed the three steps of the hearing test.

\section{Exclusion criteria}

1. Atresia or stenosis of external ear canal - both ears.

2. Not allowed by parents.

3. Referred to other hospitals or incomplete follow-up.

4. Death.

\section{Statistical analysis}

The statistical analyses were descriptive statistics, univariate and multivariate risk regression analysis. Descriptive statistics were used to present characteristics of infants included in this study. Univariate comparison of baseline characteristics between high-risk infants group and normal infants group was performed using frequency and percent distribution. Exact probability test for categorical variables, and independent Student's $t$-test or Wilcoxon rank sum test, as appropriate, were used for continuous variables. The risk factors were analyzed using regression for risk ratio (RR). For all statistical tests, $P$-value less than 0.05 were considered as significant. All analyses were conducted using Stata ${ }^{\circledR}$ version 11.0 (StataCorp LP, College Station, TX, USA).

\section{Study procedure}

This study was approved by the Faculty of Medicine Ethics Council Chiang Mai University Thailand and written informed consent was obtained in all cases. The hearing test was completed in three steps. The automated and conventional OAE tests were evaluated in the first two steps and auditory brainstem response $(\mathrm{ABR})$ was evaluated in the third stage. Newborns were assessed using the automated OAE test within 2-3 days before hospital discharge or within 1 month of age. The Madsen Accuscreen Pro T is the mode for self-operating ascertainment of transient evoked OAE and gives a "pass" or a "refer" result. If the result was a "refer", the infants were rescreened by conventional OAEs at third month of age. If the infant presented yet another "refer", then they were retested with ABR. Children's recognition of, and risk factors of hearing deterioration, evaluating outcome with automated OAEs, conventional OAEs, and ABR were grouped and analyzed. Parameters recorded in this study were: number of infants, sex, maternal age, maternal disease, type of birth, gestational age, birth weight, APGAR score, level of hearing loss, cochlear implant, auditory training, hearing aid fitting, counseling, use of breathing machine, ototoxic exposure, family history of congenital hearing loss, severe hyperbilirubinemia, sepsis, meningitis, intrauterine congenital anomaly, OAE test results at first month, OAE test results at third month, and $\mathrm{ABR}$ at third month.

\section{Results}

During the study period, 3,120 infants were recruited. There were $1,534(49.2 \%)$ boys and 1,586 (50.8\%) girls. One hundred and thirty five infants $(4.3 \%)$ failed the conventional OAE test and five infants' results $(3.7 \%)$ were confirmed by ABR. Table 1 showed the basic characteristic of the infants. Univariable risk regression of risk factors of the hearing loss of infants (aged 3 months) were conducted. The risk factors of these infants were sepsis (RR 27.6, 95\% confidence interval [CI] 19.6-38.7), family history of innate sensorineural hearing deterioration (RR 25.5, 95\% CI 14.4-45.1), use of breathing machine $>5$ days (RR 25.2, 95\% CI 18.0-35.3), 
Table I Characteristics of study subjects $(n=3,120)$

\begin{tabular}{|c|c|c|c|c|c|}
\hline \multirow[t]{3}{*}{ Characteristics } & \multicolumn{4}{|c|}{$\begin{array}{l}\text { Auditory brainstem } \\
\text { response at } 3 \text { months }\end{array}$} & \multirow[t]{3}{*}{$P$-value } \\
\hline & \multicolumn{2}{|c|}{$\begin{array}{l}\text { Hearing } \\
\text { loss }(n=135)\end{array}$} & \multicolumn{2}{|c|}{$\begin{array}{l}\text { Normal } \\
(n=2,985)\end{array}$} & \\
\hline & $\mathbf{N}$ & $\%$ & $\mathbf{N}$ & $\%$ & \\
\hline Maternal age (years) & & & & & $<0.001$ \\
\hline$<20$ & 5 & 3.7 & 59 & 1.9 & \\
\hline $20-35$ & 109 & 80.7 & 2,879 & 96.5 & \\
\hline$>35$ & 21 & 15.6 & 47 & 1.6 & \\
\hline Maternal diseases & & & & & $<0.001$ \\
\hline No & 124 & 91.8 & 2,947 & 98.7 & \\
\hline Yes & 11 & 8.2 & 38 & 1.3 & \\
\hline Intrauterine infection & & & & & $<0.001$ \\
\hline No & 130 & 96.3 & $2,98 ।$ & 99.9 & \\
\hline Yes & 5 & 3.7 & 4 & 0.1 & \\
\hline $\begin{array}{l}\text { Family history of congenital } \\
\text { sensorineural hearing loss }\end{array}$ & & & & & $<0.001$ \\
\hline No & 122 & 90.4 & 2,985 & 100.0 & \\
\hline Yes & 13 & 9.6 & 0 & 0.0 & \\
\hline Birth weight (g) & & & & & $<0.001$ \\
\hline$<1,500$ & 11 & 8.2 & 58 & 2.0 & \\
\hline $\mathrm{I}, 500-2,500$ & 25 & 18.5 & 323 & 10.8 & \\
\hline$>2,500$ & 99 & 73.3 & 2,604 & 87.2 & \\
\hline APGAR score at 5 minutes & & & & & $<0.001$ \\
\hline Normal $(\geq 6)$ & 64 & 47.4 & 2,909 & 97.5 & \\
\hline Abnormal $(<6)$ & 71 & 52.6 & 76 & 2.5 & \\
\hline Craniofacial anomalies & & & & & $<0.001$ \\
\hline No & 105 & 77.8 & 2,964 & 99.3 & \\
\hline Yes & 30 & 22.2 & 21 & 0.7 & \\
\hline $\begin{array}{l}\text { Use of breathing machine } \\
>5 \text { days }\end{array}$ & & & & & $<0.001$ \\
\hline No & 65 & 48.1 & 2,927 & 98.1 & \\
\hline Yes & 70 & 51.9 & 58 & 1.9 & \\
\hline Meningitis & & & & & $<0.001$ \\
\hline No & 120 & 88.9 & 2,983 & 99.9 & \\
\hline Yes & 15 & II.I & 2 & 0.1 & \\
\hline Sepsis & & & & & $<0.001$ \\
\hline No & 75 & 55.6 & 2,957 & 99.1 & \\
\hline Yes & 60 & 44.4 & 28 & 0.9 & \\
\hline Ototoxic exposure & & & & & $<0.001$ \\
\hline No & 58 & 43.0 & 2,899 & 97.1 & \\
\hline Yes & 77 & 57.0 & 86 & 2.9 & \\
\hline $\begin{array}{l}\text { Severe hyperbilirubinemia } \\
\text { (term } \geq 18 \mathrm{mg} / \mathrm{dL} \text {, preterm } \\
\geq 15 \mathrm{mg} / \mathrm{dL} \text { ) }\end{array}$ & & & & & $<0.001$ \\
\hline No & 92 & 68.1 & 2,964 & 99.3 & \\
\hline Yes & 43 & 31.9 & 21 & 0.7 & \\
\hline
\end{tabular}

Abbreviations: APGAR, Activity Pulse Grimace Appearance and Respiration.

ototoxic exposure (RR 24.1, 95\% CI 17.1-33.9), meningitis (RR 22.8, 95\% CI 13.3-39.0) as shown in Table 2. Multivariable risk regression of risk factors of the hearing loss of infants (aged 3 months) was analyzed. The risk factors at 3 months were birth weight 1,500-2,500 g (RR 1.6, 95\% CI 1.1-2.6), APGAR score $<6$ at 5 minutes (RR 2.2, 95\% CI
Table 2 Univariable risk regression of risk factors of the hearing loss of infants (aged 3 months)

\begin{tabular}{|c|c|c|c|}
\hline Characteristics & Risk ratio & $95 \% \mathrm{Cl}$ & $P$-value \\
\hline Intrauterine infection & 13.3 & $5.4-32.5$ & $<0.001$ \\
\hline $\begin{array}{l}\text { Family history of congenital } \\
\text { sensorineural hearing loss }\end{array}$ & 25.5 & $14.4-45 . \mid$ & $<0.001$ \\
\hline Birth weight $<1,500 \mathrm{~g}$ & 4.3 & $2.3-8.1$ & $<0.001$ \\
\hline Birth weight $1,500-2,500 \mathrm{~g}$ & 2.0 & $1.3-3.0$ & 0.003 \\
\hline APGAR score $<6$ at 5 minutes & 22.4 & $|6.0-3| .4$ & $<0.001$ \\
\hline Craniofacial anomalies & 17.2 & II.4-25.8 & $<0.001$ \\
\hline Use of breathing machine $>5$ days & 25.2 & $18.0-35.3$ & $<0.001$ \\
\hline Meningitis & 22.8 & $13.3-39.0$ & $<0.001$ \\
\hline Sepsis & 27.6 & $19.6-38.7$ & $<0.001$ \\
\hline Ototoxic exposure & 24.1 & $17.1-33.9$ & $<0.001$ \\
\hline $\begin{array}{l}\text { Severe hyperbilirubinemia (term } \\
\geq 18 \mathrm{mg} / \mathrm{dL} \text {, preterm } \geq 15 \mathrm{mg} / \mathrm{dL} \text { ) }\end{array}$ & 22.3 & $15.5-32.1$ & $<0.001$ \\
\hline
\end{tabular}

Abbreviation: $\mathrm{Cl}$, confidence interval; APGAR, Activity Pulse Grimace Appearance and Respiration.

1.1-4.4), craniofacial anomalies (RR 2.5, 95\% CI 1.6-4.2), Risk factors for hearing loss sepsis (RR 1.8, 95\% CI 1.0-3.2), and ototoxic exposure (RR 4.1, 95\% CI 1.9-8.6) as shown in Table 3.

\section{Discussion}

The aim was to define the risk factors for infants (aged 3 months) with hearing loss within a suitable period of time and to provide guidelines to prevent the evolution of hearing loss and its advancement. ${ }^{1,3,6,7}$ Accurate diagnosis of hearing loss within the first 3 months of life expands the possibility of proper auditory processing and conversation and diminishes neuropsychological obstacles. ${ }^{2}$ Automated OAE tests, conventional OAE tests, and ABR hearing screening for infants (aged 3 months) is possible and can assist to identify hearing

Table 3 Multivariable risk regression of risk factors of the hearing loss of infants (aged 3 months)

\begin{tabular}{|c|c|c|c|}
\hline Risk factors & Risk ratio & $95 \% \mathrm{Cl}$ & $P$-value \\
\hline Intrauterine infection & 2.3 & $0.8-6.0$ & 0.103 \\
\hline $\begin{array}{l}\text { Family history of congenital } \\
\text { sensorineural hearing loss }\end{array}$ & 1.9 & $0.9-3.7$ & 0.064 \\
\hline Birth weight $<1,500 \mathrm{~g}$ & 1.4 & $0.7-2.8$ & 0.288 \\
\hline Birth weight $1,500-2,500 \mathrm{~g}$ & 1.6 & I.I-2.6 & $0.029 *$ \\
\hline APGAR score $<6$ at 5 minutes & 2.2 & I.I-4.4 & $0.029 *$ \\
\hline Craniofacial anomalies & 2.5 & $1.6-4.2$ & $<0.00 I^{*}$ \\
\hline Use of breathing machine $>5$ days & 1.4 & $0.7-3.1$ & 0.319 \\
\hline Meningitis & 0.9 & $0.5-1.8$ & 0.838 \\
\hline Sepsis & 1.8 & $1.0-3.2$ & $0.045^{*}$ \\
\hline Ototoxic exposure & 4.1 & $1.9-8.6$ & $<0.00 I^{*}$ \\
\hline $\begin{array}{l}\text { Severe hyperbilirubinemia (term } \\
\geq 18 \mathrm{mg} / \mathrm{dL} \text {, preterm } \geq 15 \mathrm{mg} / \mathrm{dL} \text { ) }\end{array}$ & 1.7 & $0.9-3.2$ & 0.068 \\
\hline
\end{tabular}

Note: $* P<0.05$.

Abbreviation: $\mathrm{Cl}$, confidence interval; APGAR, Activity Pulse Grimace Appearance and Respiration. 
loss faster than before. ${ }^{8,9}$ The frequency of moderate to severe hearing loss in both normal and high-risk groups is an indication that universal hearing tests should be performed. The presence of one hearing ear does permit normal auditory and conversational development. ${ }^{10}$ On the other hand, automated OAE tests may present false passes in cases with brain or central hearing damage. Nevertheless, $20 \%$ of normal hearing infants did not pass a conventional OAE test and had to be re-evaluated with ABR. ${ }^{11}$ In the study of Valkama et al, they found the most prevalent risk factors in infants who did not pass hearing tests were low birth weight and premature birth, ${ }^{12}$ ototoxic exposure, and craniofacial anomalies, similar to what the authors of the current study found. Low birth weight and premature birth are not necessarily risk factors if the doctors can provide curative treatment to the newborn in an intensive care unit so that the possibility of hearing loss can be decreased. In view of cases with progressive hearing loss problems, not only signs and symptoms' follow-up, but a hearing evaluation is also required to identify cases with hearing deterioration. Aminoglycosides are a risk factor when applied in long courses or in conjunction with loop diuretics. Some studies ${ }^{12,13}$ recommend that aminoglycosides are not a significant risk factor for hearing loss when the infant's serum levels are uninterruptedly observed. Other highrisk factors ${ }^{8,14-17}$ considered are ototoxic exposure $41.3 \%$, severe asphyxia $40 \%$, mechanical ventilation $>5$ days $40 \%$, premature infant $34.1 \%$, and severe hyperbilirubinemia $26.4 \%$, similar to the study by Timruangvet performed at the department of otolaryngology, Roi - Et Hospital, Thailand. ${ }^{18}$ Vohr et al, ${ }^{19}$ in their study, discovered the most frequent high-risk factors for hearing loss are ototoxic exposure $44.4 \%$, very low birth weight $17.8 \%$, assisted mechanical ventilation $>5$ days $16.4 \%$, and severe birth asphyxia $13.9 \%$. There were implications that bacterial meningitis caused permanent hearing loss in both ears, which was discovered in $33 \%$ of the infants. ${ }^{17,20}$ Risk factors relating to bilateral hearing loss were appraised by univariate and multivariate risk regression analysis. Univariate analysis in this study showed that high-risk factors related to hearing loss included intrauterine infection, family history of congenital sensorineural hearing loss, birth weight $<1,500 \mathrm{~g}$, birth weight 1,500-2,500 g, APGAR score $<6$ at 5 minutes, craniofacial anomalies, use of breathing machine for $>5$ days, meningitis, sepsis, ototoxic exposure, and severe hyperbilirubinemia (term $\geq 18 \mathrm{mg} / \mathrm{dL}$, preterm $\geq 15 \mathrm{mg} / \mathrm{dL}$ ). Multivariate risk regression analysis in this study showed that five independent risk factors at 3 months were related to bilateral hearing loss, including low birth weight ( $\mathrm{RR}=1.6,95 \% \mathrm{CI} 1.1-2.6)$,
APGAR score $<6$ at 5 minutes $(\mathrm{RR}=2.2,95 \%$ CI 1.1-4.4), craniofacial anomalies ( $\mathrm{RR}=2.5,95 \%$ CI 1.6-4.2), sepsis $(\mathrm{RR}=1.8,95 \%$ CI 1.0-3.2), and ototoxic exposure $(\mathrm{RR}=4.1$, 95\% CI 1.9-8.6). For any hearing test program, incorrect "fail" test outcomes may cause consequences such as parental misconception and worry, and needless operations or other treatment in an infant who hears normally. Nevertheless, the definite analysis of progressive hearing deterioration must be performed carefully and in collaboration with an otolaryngologist, pediatrician, audiologist, and expanded audiological investigation, as well as ABR, and behavioral assessment at 36 weeks in order to confirm diagnosis., ${ }^{4-21-23}$ Some children may be diagnosed with deferred onset or earlier undiagnosed hearing deterioration. ${ }^{23-25}$ Children with the deferred onset type had a higher frequency of low birth weight and premature birth, craniofacial anomalies, and ototoxic exposure. ${ }^{26-28}$ Nevertheless, it was confirmed that the screening criteria from the Joint Committee of Infant Hearing were able to identify most of the high-risk infants with hearing loss but that the screening of healthy neonates must be started. ${ }^{6,29,30}$

OAE tests and ABR testing are greatly appropriate as screening tests because they can be performed at a very early age. Nevertheless, when interpreting the results, physicians should consider all the possible auditory pathway deficiencies. The definite diagnosis of permanent hearing loss is a combination of otolaryngological, audiological, and expanded audiological investigation, as well as diagnostic ABR, and behavioral assessment at 3 months to confirm electrophysiological diagnosis. The recommended test for all infants was ABR and middle ear function using acoustical impedance/admittance by the expert team (otologists, pediatricians, audiologists, audiological technicians, and nurses). Interpretation of otologic and audiologic results should be performed by an otolaryngologist.

\section{Conclusion}

This study concluded that, in Northern Thailand, an APGAR score $<6$ at 5 minutes, low birth weight, craniofacial anomalies, sepsis, and ototoxic exposure are the risk factors of bilateral hearing loss in infants (aged 3 months). Infants with these risk factors should receive special attention and proper treatment should be attained to handle these risk factors. As an outcome, it is currently suggested that infirmary/physicians/ general practitioners/health action centers/polyclinics carry out universal hearing screening in all children before 36 weeks of life. The public health policy of Thailand regarding a universal hearing screening program is important for the prevention of disability and to enhance people's quality of life. 


\section{Acknowledgments}

The researchers wish to acknowledge DrWanchai Tangarommun, the otolaryngologist of Buddhachinaraj Hospital, Dr Rungjai Chareonsil, the otolaryngologist of Sawanpracharuk Hospital, and the director of Uttaradit Hospital, Buddhachinaraj Hospital, and Sawanpracharuk Hospital for their support in this study.

\section{Disclosure}

The authors report no conflicts of interest in this work.

\section{References}

1. Cone-Wesson B, Vohr BR, SiningerYS, et al. Identification of neonatal hearing impairment: infants with hearing loss. Ear Hear. 2000;21(5): 488-507.

2. Yoshikawa S, Ikeda K, Kudo T, Kobayashi T. The effects of hypoxia, premature birth, infection, ototoxic drugs, circulatory system and congenital disease on neonatal hearing loss. Auris Nasus Larynx. 2004;31(4):361-368.

3. Wroblewska-Seniuk K, Chojnacka K, Pucher B, Szczapa J, Gadzinowski J, Grzegorowski M. The results of newborn hearing screening by means of transient evoked otoacoustic emissions. Int $J$ Pediatr Otorhinolaryngol. 2005;69(10):1351-1357.

4. Jariengprasert C, Sriwanyong S, Kasemsuwan L, Supapannachart S. Early identification of hearing loss in high-risk newborns and young children in Thailand by using transient otoacoustic emissions (TEOAEs). Asia Pacific Journal of Speech, Language and Hearing. 2002;7(1):1-9.

5. Abdul Hadi K, Salahaldin A, Al Qahtani A, et al. Universal neonatal hearing screening: six years of experience in Qatar. Qatar Med J. 2013; 2012(2):42-50.

6. No authors listed. Joint Committee on Infant Hearing 1994 Position Statement. American Academy of Pediatrics Joint Committee on Infant Hearing. Pediatrics. 1995;95(1):152-156.

7. Newborn and infant hearing loss: detection and intervention. American Academy of Pediatrics. Task Force on Newborn and Infant Hearing, 1998-1999. Pediatrics. 1999;103(2):527-530.

8. Vatovec J, Velickovic Perat M, Smid L, Gros A. Otoacoustic emissions and auditory assessment in infants at risk for early brain damage. Int $J$ Pediatr Otorhinolaryngol. 2001;58(2):139-145.

9. Yoon PJ, Price M, Gallagher K, Fleisher BE, Messner AH. The need for long-term audiologic follow-up of neonatal intensive care unit (NICU) graduates. Int J Pediatr Otorhinolaryngol. 2003;67(4):353-357.

10. Srisuparp P, Gleebbur R, Ngerncham S, Chonpracha J, Singkampong J. High-risk neonatal hearing screening program using automated screening device performed by trained nursing personnel at Siriraj Hospital: yield and feasibility. J Med Assoc Thai. 2005;88 Suppl 8:S176-S182.

11. Geal-Dor M, Levi H, Elidan Y, Arad I. The hearing screening program for newborns with otoacoustic emission for early detection of hearing loss. Harefuah. 2002;141(7):586-590, 668. Hebrew.

12. Valkama AM, Laitakari KT, Tolonen EU, Vayrynen MR, Vainionpaa LK, Koivisto ME. Prediction of permanent hearing loss in high-risk preterm infants at term age. Eur J Pediatr. 2000;159(6):459-464.
13. Nozza RJ, Sabo DL, Mandel EM. A role for otoacoustic emissions in screening for hearing impairment and middle ear disorders in schoolage children. Ear Hear. 1997;18(3):227-239.

14. Finckh-Kramer U, Gross M, Bartsch M, Kewitz G, Versmold H, Hess M. Hearing screening of high risk newborn infants. HNO. 2000;48(3):215-220. German.

15. Hess M, Finckh-Kramer U, Bartsch M, Kewitz G, Versmold H, Gross M. Hearing screening in at-risk neonate cohort. Int $J$ Pediatr Otorhinolaryngol. 1998;46(1-2):81-89.

16. Sun JH, Li J, Huang P, Bu J, Xu ZM, Li J, et al. Early detection of hearing impairment in high-risk infants of NICU. Zhonghua Er Ke Za Zhi. 2003;41(5):357-359. Chinese.

17. Charuvanij A, Visudhiphan P, Chiemchanya S, Tawin C. Sensorineural hearing loss in children recovered from purulent meningitis: a study in Thai children at Ramathibodi Hospital. J Med Assoc Thai. 1990;73(5):253-257.

18. Timruangvet A. High Risk Infant Hearing Screening at Roi-Et Hospital. Khon Kaen Hospital Medical Journal. 2007;31(2):165-173.

19. Vohr BR, Widen JE, Cone-Wesson B, et al. Identification of neonatal hearing impairment: characteristics of infants in the neonatal intensive care unit and well-baby nursery. Ear Hear. 2000;21(5):373-382.

20. Prasansuk $S$. Incidence/prevalence of sensorineural hearing impairment in Thailand and Southeast Asia. Audiology. 2000;39(4):207-211.

21. Johnson JL, White KR, Widen JE, et al. A multicenter evaluation of how many infants with permanent hearing loss pass a two-stage otoacoustic emissions/automated auditory brain-stem response newborn hearing screening protocol. Pediatrics. 2005;116(3):663-672.

22. Norton SJ, Gorga MP, Widen JE, et al. Identification of neonatal hearing impairment: evaluation of transient evoked otoacoustic emission, distortion product otoacoustic emission, and auditory brain stem response test performance. Ear Hear. 2000;21(5):508-528.

23. Yoshinaga-Itano C. Levels of evidence: universal newborn hearing screening (UNHS) and early hearing detection and intervention systems (EHDI). J Commun Disord. 2004;37(5):451-465.

24. Robertson CM, Tyebkhan JM, Peliowski A, Etches PC, Cheung PY. Ototoxic drugs and sensorineural hearing loss following severe neonatal respiratory failure. Acta Paediatr. 2006;95(2):214-223.

25. Jacobson J, Jacobson C. Evaluation of hearing loss in infants and young children. Pediatr Ann. 2004;33(12):811-821.

26. Nance WE, Lim BG, Dodson KM. Importance of congenital cytomegalovirus infections as a cause for pre-lingual hearing loss. J Clin Virol. 2006;35(2):221-225.

27. Morton CC, Nance WE. Newborn hearing screening: a silent revolution. N Engl J Med. 2006;354(20):2151-2164.

28. Khaimook W, Chayarpham S, Dissaneevate S. The High-Risk Neonatal Hearing Screening Program in Songklanagarind Hospital. J Med Assoc Thai. 2008;91(7):1038-1042.

29. Chu K, Elimian A, Barbera J, Ogburn P, Spitzer A, Quirk JG. Antecedents of Newborn Hearing Loss. Obstet Gynecol. 2003;101(3):584-588.

30. Courtney SE, Durand DJ, Asselin JM, Hudak ML, Aschner JL, Shoemaker CT. High-frequency oscillatory ventilation versus conventional mechanical ventilation for very-low-birth-weight infants. N Engl J Med. 2002;347(9):643-652.
Journal of Multidisciplinary Healthcare

\section{Publish your work in this journal}

The Journal of Multidisciplinary Healthcare is an international, peerreviewed open-access journal that aims to represent and publish research in healthcare areas delivered by practitioners of different disciplines. This includes studies and reviews conducted by multidisciplinary teams as well as research which evaluates the results or conduct of such teams or

\section{Dovepress}

healthcare processes in general. The journal covers a wide range of areas and welcomes submissions from practitioners at all levels, from all over the world. The manuscript management system is completely online and includes a very quick and fair peer-review system. Visit http://www.dovepress.com/testimonials.php to read real quotes from published authors. 